\title{
OCIO, PEREZA Y EDUCACIÓN: UN ACERCAMIENTO A LA EJERCITACIÓN EN EL BIEN
}

LEISURE, LAZINESS AND EDUCATION: AN APPROACH TO EXERCISE IN GOOD

LAZER, PREGUIÇA E EDUCAÇÃO: UMA APROXIMAÇÃO À EXERCITAÇÃO NO BEM

Andrés Díaz Velasco ${ }^{1}$

Carolina Guerrero Reyes ${ }^{2}$

Resumen

Este artículo explora la tesis según la cual, la relación entre el ocio, la pereza y la educación depende de la noción de Bien que, desde la Temprana Edad Media, se ha venido imponiendo en las sociedades occidentales. En la primera parte, se describirá el planteamiento del problema, en cuanto a la ambigüedad terminológica del concepto de ocio. En la segunda, se analizará un sentido posible de la relación entre el ocio, la educación y la pereza. Y, finalmente, se describirán los derroteros investigativos (ocio como forma de vivir para modificar las escuelas) que se han producido conforme a estas afirmaciones.

Palabras claves: educación; ocio; recreación; ejercicio; pereza; bien

Abstract

This article explores the thesis that the relationship between leisure, laziness and education depends on the notion of Good imposed in Western societies since the Early Middle Ages. In the first part, we describe the problem in terms of the terminological ambiguity of the concept of leisure. In the second, we analyze a possible meaning of the relationship between leisure, education and laziness. Finally, we describe the research directions (leisure as a way of living to modify schools) resulting from these statements.

Keywords: education; leisure; recreation; exercise; laziness; good

Resumo

Este artigo explora a tese segundo a qual, a relação entre o lazer, a preguiça e a educação depende da noção de Bem que, desde a Baixa Idade Média, foi imposta nas sociedades ocidentais. Na primeira parte, é descrita a abordagem do problema em relação com a ambiguidade terminológica da concepção de lazer. Na segunda, analisa-se um possível sentido da relação entre o lazer, a educação e a preguiça. Finalmente, descrevem-se os rumos investigativos (lazer como forma de viver para modificar as escolas) que foram produzidos conforme estas afirmações.

Palavras chave: educação; lazer; recreação; exercício; preguiça; bem

Fecha de recepción: 29 de julio de 2016

Fecha de aprobación: 8 de febrero de 2017

Para citar este artículo:

Díaz, A y Guerrero C. (2007). Ocio, pereza y educación: Un acercamiento a la ejercitación en el Bien. Lúdica Pedagógica, (25), 127-136.

* Docente tiempo completo Universidad Pedagógica Nacional. Magister en Filosofía (Universidad del Rosario, Colombia); Licenciado en Educación Física (Universidad Pedagógica Nacional). Correo electrónico: adiazv@pedagogica.edu.co, andresdiazvelasco@gmail.com

** Docente tiempo completo Universidad Pedagógica Nacional. Estudiante de la Maestría en Desarrollo Educativo y Social (Universidad Pedagógica Nacional-CINDE); Licenciada en Español y Leguas Extranjeras (Universidad Pedagógica Nacional). Correo electrónico: cguerreror@pedagogica.edu.co, carolaguerreror@gmail.com 


\section{INTRODUCCIÓN}

Existen, por lo menos, cuatro problemáticas del campo social de la Recreación (compartidas en cierto modo por la Educación Física y por el Deporte) a las cuales hay que contrarrestar con el fin de contribuir al fortalecimiento de su(s) saber(es) disciplinar(es), y no solo compartidas con otras ciencias, sino que, además, otros términos como el ocio, la holgazanería y la pereza se enmarcan, casi que unificados, alrededor de un mismo concepto. Por eso, en primer término, el problema de los lugares comunes, es decir, de las nociones que suelen usarse sin un profundo análisis, sino, más bien, como si fueran verdades evidentes. Entre estos están, por ejemplo, el hecho de que el ocio se reparta indefectiblemente entre el ideal griego, la holgazanería o la pereza, y el no-hacer-nada; o bien, cuando es en sí mismo, el que se encuentre en un nivel de importancia académica y social, por encima de otros términos como, justamente, pereza y holganza. Otro caso de lugar común es la consideración de la educación como un fenómeno exclusivamente humano y centrado solo en la escolaridad, cuestión que ya ha sido reevaluada en los estudios educativos de Illich (2006) y los estudios etológicos realizados por De Waal (2002).

En segundo lugar, y como consecuencia del primero, se tiene el problema de la referencia constante a la época grecorromana como escenario de invención de su existencia, es decir, la remisión a la forma de vivir de los antiguos griegos y romanos como testimonio certero de la actualidad de la Recreación (la Educación Física y el Deporte). Entre quienes proceden de ese modo, podrían considerarse a Rodríguez (1998), a Acosta (2002), a Forero-Nogués (2004), Bolaños (2005) y a Bonilla (s. f.). Esta perspectiva parece suponer que, al enunciar tan lejano y solemne pasado, puede darse por sentada la importancia (o el estatus) de estos campos sin profundizar aspectos conflictivos de tal linealidad histórica, como lo han hecho ya Meinel (1998), Vigarello (2005a) y Pedraz (2006).

Tercero, es problemática la idea según la cual los conceptos, en general, poseen una historia a partir de un origen preciso, desde el que se desarrollan o evolucionan. De acuerdo con ello, la Recreación vendría a ser un estado evolutivo de la noción de ocio (scholé en griego y otium en latín), un punto culmen en el entendimiento y práctica de un saber referido al descanso, al disfrute y a la diversión (Sue, 1987). De igual modo, no se concibe al ejercicio más que como un mero movimiento corporal sistemático, en el que el cuerpo resulta ser un instrumento mecánico y perfectible. Sin duda, esta noción de la historia no aplica solo a los campos de la Recreación, la Educación Física y el Deporte, sino también, analizada críticamente por Nietzsche, que va a ser luego sistematizada por filósofos como Foucault (2008) y De Landa (2011), y, asimismo, por historiadores como Chartier (2006). Mas, teniendo en cuenta que la Recreación, en cuanto campo de saber, se viene constituyendo hace muy poco, se debe tener cuidado y, preferiblemente, partir de la hipótesis de que el ocio, así como la educación y el ejercicio, no son conceptos fáciles de asir conforme a una mirada lineal de la historia, requiriendo por ello un estudio de corte genealógico.

Finalmente, existe también el problema del establecimiento de una estrecha relación entre la recreación, el tiempo libre y la pereza, la cual se balancea sobre la noción de ocio que se emplee. Así, a pesar de los diversos estudios sobre sus diferencias (Gerlero, 2005; Elizalde y Gomes, 2010, etc.), tales conceptos continúan siendo tratados tanto en el lenguaje ordinario como, incluso, en algunos estudiosos, como si trataran de lo mismo o, por lo menos, como si fueran parte de una misma (y única) historia en la que adquieren sentido al contraponerse al trabajo, a lo serio y al esfuerzo como bienes absolutos. Sin duda alguna, entre estas nociones impera una relación muy particular, pero parece ignorarse cuál es exactamente, de dónde proviene y por qué razón emergió. Sin este conocimiento mínimo, no tiene mucho sentido dar por hecho la relación ${ }^{3}$.

Así las cosas, este trabajo pretende ser parte de los análisis que, sin adoptar medidas globalizantes o totalitarias, emprenden una revisión crítica de las problemáticas evidenciadas y sugieren orientaciones de investigación ${ }^{4}$.

3 Tomando distancia de los trabajos académicos que ya han definido el porqué de las diferencias, pese a sus notables esfuerzos, aquí se toma una línea de trabajo alternativa, basada en el análisis conceptual de Deleuze y Guattari, según el cual, "Todo concepto remite a un problema, a unos problemas sin los cuales carecería de sentido, y que a su vez solo pueden ser despejados o comprendidos a medida que se vayan solucionando. [...] todo concepto tiene una historia, aunque esta historia zigzaguee, o incluso llegue a discurrir por otros problemas o por planos diversos. En un concepto hay, las más de las veces, trozos o componentes procedentes de otros conceptos, que respondían a otros problemas y suponían otros planos" (2005, p. 23).

4 Este escrito hace parte de los avances que se desarrollan al interior del proyecto de investigación "Docencia, ocio y formación: ¿qué de la época grecorromana puede servir hoy día?", aprobado por la Subdirección de Gestión de Proyectos-Centro de Investigaciones de la Universidad Pedagógica Nacional para la vigencia 2016, 
Se asume, entonces, que el periodo neurálgico para comprender la lógica interna de la asociación del ocio a un estado de inactividad displicente y malsana es la Alta Edad Media, debido a que fue allí cuando, al discurso cristiano, se aliaron el ocio y la pereza en contraposición a los denominados ejercicios espirituales, prácticas desde entonces vinculadas con la educación (Aries, 1987). No obstante, si esto es así, debe comprenderse cómo se percibía el ocio en la época que antecede al periodo en cuestión, y analizar sus implicaciones en el tránsito. Mas, qué importancia tendría este análisis si no se contrastara con el presente, a partir del cual, precisamente, adquiere sentido todo el debate.

De este modo, a continuación, se desarrollará la tesis según la cual la relación entre el ocio, la pereza y la educación depende de la noción de Bien que, desde la Temprana Edad Media, se ha venido imponiendo prácticamente a las sociedades occidentales. En la primera parte, se describirá el planteamiento del problema. En la segunda, se analizará un sentido posible de la relación entre el ocio, la educación y la pereza. Y, al final, ya que no hay forma de concluir, se describirán los derroteros investigativos que se han producido conforme estas afirmaciones. Se espera que este artículo siga contribuyendo al fortalecimiento del campo social y académico de la Recreación, toda vez que las grandes tareas se logran a partir de pequeños ejercicios.

\section{PLANTEAMIENTO DEL PROBLEMA: EL SENTIDO DEL ENTRECRUZAMIENTO}

Aunque suela utilizarse el término ocio, en el lenguaje corriente, como sinónimo de holgazanería o vagancia, expresando con ello un sentido peyorativo, casi insultante sobre la ociosidad, en los Estudios sobre Ocio, no solo en lengua española, este ha adquirido una connotación totalmente distinta, positiva y honorífica. Pero, como suele pensarse que el trato peyorativo solo pasa dentro de la tradición religiosa católica, debe afirmarse que esa idea fue planteada asimismo por autores como Kant y Marx, e incluso, en nuestros días, por Sloterdijk (2012), en una tesis que no resulta fácil de comprender porque da pie para ambigüedades antropológicas.

con código FEF-442-16. Los autores de este texto fungen como investigadores principales del proyecto, en el que se cuenta además con la participación de tres monitores de investigación y un practicante monitor. Asimismo, el artículo delinea la investigación que el actual proyecto busca continuar en vigencias futuras.
Por ello, que ciertos autores elogien la ociosidad y la pereza no significa que su concepción sea la más apropiada, o la única que convenga dentro de los estudios sobre ocio y recreación.

Por otro lado, el vocablo ejercicio resulta cada vez mejor visto dentro de una sociedad como la nuestra, que pretende alcanzar un alto grado de salud y vigor a través del estar en forma, mientras en distintos círculos académicos (relacionados con la lentitud, el bienestar y el anti-consumismo) se ejerce una fuerte resistencia a todo aquello que, producto del capitalismo, va llevando a los hombres a convertirse en extremistas de la rutina (Bruckner, 2001). Por su parte, Sloterdijk también se pronuncia sobre el ejercicio, pero, una vez más, indudablemente su tesis no puede asociarse con las sociedades deportivistas y gimnásticas (Vigarello y Holt, 2005). En una palabra, al sol de hoy, la oposición entre la actividad constante y veloz (y no solo el trabajo) se sigue oponiendo a una suerte de ralentización de la vida (ociosidad, idleness, laziness, oisiveté, paresse...).

Por ello, la educación se encuentra en un gran conflicto: o bien se orienta hacia el fin del entrenamiento, del esfuerzo dedicado -reforzando, así, el establecimiento de una sociedad eficientista en la que se funden (o confunden) el resultado con el proceso, así como el consumo con la producción-, o bien, se resiste a ello, proponiendo un escenario de ociosidad. En otras palabras, se adecúa definitivamente a su contexto socioeconómico o asume decididamente su raíz griega. Lo primero se le impone, se dirá, gubernamental y legislativamente, pero es justo tras esta imposición cuando hay que pensar los fines de la educación y el tipo de sociedad que se quiere contribuir a formar. Sobre lo que se alcanzaría siguiendo tal imposición, Deleuze y Guattari (1995) han analizado la configuración de este tipo de sociedad en la que se presenta un nuevo esclavismo (como lo expresa Vega, 2007) conforme al control de los individuos a través de la promoción de un descontrolado (valga decir, imparable) estilo de vida instrumentalizado: deuda, medios electrónicos de regulación comportamental y de vigilancia, un ojo absoluto a través de tales dispositivos, exacerbación del sector servicios y su tipo de inestabilidad contractual, etc.

Ya Estanislao Zuleta (2010) había dicho que, únicamente en una sociedad esclavista, hiper-productivista, es mal vista la pereza. Este tipo de sociedad se sostiene en la 
idea cristiana de que el trabajo es el único medio por el cual el hombre se hace hombre, señor de la naturaleza (como reza el Génesis 1:26) y obediente de Dios, quien ha creado al trabajo como tarea específicamente humana. Siguiendo a Abenshushan (2013), vemos aquí el golpe de gracia dado por Caín, el homo faber, a Abel, el homo ludens. Bajo esta concepción, el ocio (como pereza) es entendido, entonces, como un vicio o, tal como suele decirse, madre de todos los vicios. De allí que no sean pocos los que denigren de este, al punto que en la sabiduría popular se diga con regularidad, contra pereza, diligencia. No hay que negar que, como Lafargue (2004) ha dejado ver, con la industrialización y el deseo imparable de usufructo, la noción de trabajo adquirió un matiz más poderoso, en la medida en que se revistió como derecho y, a la vez, como acción dignificante, por lo que su contraparte esencial se reduciría a la imprecación.

Sin embargo, haciendo un análisis más detallado sobre los términos, parece que tal oposición realmente pende de un hilo. Si entre los grecorromanos, por ejemplo, el ocio no poseía ningún sentido peyorativo, sino todo lo contrario, habría que afirmar que se debía a su intrincada relación con la educación y con el ejercicio. Como ha mostrado Pieper (2003), ocio y educación, de hecho, venían a significar prácticamente lo mismo; y, el ejercicio, si se entiende por él el ejercicio físico que realiza un atleta, o bien, el ejercicio intelectual que realiza un sofista, solo es posible gracias al ocio. Es más, en Séneca, claramente, el ocio es un ejercicio, o una práctica de sí, -si se prefiere- en términos foucaultianos. Por ello, es dudoso que, entre los griegos, como se afirma convencionalmente, haya sido mal visto el trabajo como tal -debido a que era una actividad típica de los esclavos u hombres no-libres, se dice-; o bien, que entre los romanos, el negocio no se haya considerado como otra cosa más que la negación del ocio. Indudablemente, el concepto de trabajo no genera menos problemas que el de ocio, sobre el cual, de hecho, recaían para entonces diferentes juicios (cf. Applebaum, 1992).

Ahora bien, de acuerdo con este abanico de significaciones y formas de vivir, entre los griegos y las sociedades modernas occidentales hay un largo periodo de reconfiguración de las prácticas vitales que dio lugar a una resignificación del ocio, del trabajo, de la educación y del ejercicio. Todavía no es claro cómo fue este proceso en detalle, aunque, se afirma con regularidad -siguiendo los planteamientos de la historiografía convencional- que se trató meramente de un oscurantismo producto de la imposición religiosa. Prácticamente, el nulo desarrollo de la ciencia, el establecimiento de los siete pecados capitales y los vicios a los que dan lugar, la organización dogmática y bélica de un imperio basado en la fe y el empleo de instituciones que persiguieron y mataron a quienes consideraban disidentes, suele decirse, marcaron sustancialmente el tipo de vida de la época.

No obstante, estas apreciaciones tan generales no permiten encontrar las fuerzas en disputa, el cruce de herencias culturales, el choque de creencias religiosas y la creación de prácticas que siguieron normas precisas de comportamiento durante ese periodo. De hecho, el desarrollo del pensamiento, tanto científico como filosófico y artístico, no se detuvo, dándose precisamente allí la constitución de las más importantes universidades del mundo, muchas de las cuales aún siguen en pie. El énfasis en la traducción de los clásicos griegos y latinos, además de los entrelazamientos con el pensamiento árabe, constituyeron un escenario rico en ideas. Por tanto, resulta más bien paradójico el hecho de que el ocio, en el sentido cristiano, haya sido criticado mientras se practicaba en los monasterios en el sentido griego ${ }^{5}$. Habría que connotar como antropotécnica a la vita contemplativa (u otio entre los latinos), para dar cuenta de su performatividad, tal como hace Sloterdijk (2012) -quien da bastantes luces al problema.

Así las cosas, la ambigüedad terminológica, consideramos, podría explicarse a partir de una noción, quizá hasta ahora externa al debate común sobre el ocio, el ejercicio y la educación, sobre la cual recae la aceptación o el rechazo acerca de lo que se hace, de aquello en lo que se gasta la vida. Se trata de la noción de Bien, la base de la construcción de todo lo demás, es decir, tanto de prácticas de vida como de normas de comportamiento, de discursos filosóficos y de acciones militares, entre otras cosas. Podría aventurarse la hipótesis que, de la idea de Bien, depende el sentido del ocio, la orientación de la educación y la promoción de ciertos ejercicios. El problema sería, entonces, si lo que se hace nos procura el Bien, si es parte del Bien, y/o si el Bien lo aprueba.

5 Esta afirmación requiere un análisis más profundo que excede los alcances del texto. La paradoja posibilita un análisis multicultural, por ejemplo, que será necesario ver en detalle para no generar confusión tras la exposición conceptual o, si se quiere, terminológica. 
¿Nos ejercitamos en el Bien o perdemos nuestro tiempo? La pregunta no es baladí, y podría reformularse así: ¿vale la pena vivir si hago esto o aquello?

La oposición entre ciertas prácticas religiosas y la pereza tiene esta pregunta como horizonte. Sin ir muy lejos, en las Confesiones de Agustín de Hipona, tanto como en las Sentencias de Pedro Lombardo, es evidente que todo gira alrededor de la idea de adorar a Dios como Bien supremo del hombre, de modo que aquello que le sea contrario es, por definición, un Mal. La imagen que parece develarse, entonces, es la de la consideración del ocio como desidia ante las actividades religiosas, la educación orientada a la formación de tales actividades, y el ejercicio como su habituación. Pascal Bruckner (2001) lo comenta del siguiente modo:

Los ejercicios espirituales llevados a cabo en cada comunidad intentaban alejar a los religiosos de la dispersión y conducirlos al camino único de la adoración divina. (...) Lutero y Calvino (que sustituyeron la oración por el trabajo e hicieron de este último un acto casi religioso) llegaron a acusar al monje de holgazán y parásito, cuando, en cierto modo, se trataba de un hombre agotado. (...) Cuando vive en la fe [para el monje] cada hora es preciosa, porque puede dedicarla toda entera a la gloria de Dios. Pero si duda o flaquea, le invade la acedía (del griego akedia, que significa indiferencia y tristeza), esa terrible enfermedad de los ascetas que los apartaba del señor y los llenaba de aflicción. Es el hastío de alguien que ha dedicado su vida a la oración y al que la oración cansa, que pierde de pronto el interés por su salvación; un mal terrible contra el que la iglesia se ha confesado impotente. (pp. 88-89).

Este estado (del alma y del cuerpo) no solo es mal visto, sino que se procura escapar a toda costa de él, porque, en el contexto religioso, tanto como en el productivista, lleva a la perdición. De este modo, el ocio o la pereza no son malos porque sí, lo son en relación con un Bien absoluto que les da forma. Todo lo demás, son asociaciones sinonímicas, usos de la lengua, juegos del lenguaje que se enredan hasta confundirlo todo bajo una misma consigna: estar a favor o estar en contra. Así las cosas, es menester revisar con más precisión y detalle esa relación que se ha establecido entre el ocio, la pereza y la educación a partir de la noción de Bien producida en la Temprana Edad Media, siempre que se desee dar cuenta de su mal-trato actual, así como de las posibilidades de transformación existencial que se abren con el estudio del ocio grecorromano y de sus proclamaciones contemporáneas.

\section{DESARROLLO DEL PROBLEMA: EL EJERCICIO DEL BIEN}

En 1975, Ramón Pérez de Ayala afirmaba que "la palabra escuela es de origen griego, y significa 'ocio'” (p.13), de un modo similar a como lo haría Josef Pieper (2003), quien escribiera que:

Ocio se dice en griego $\sigma \chi 0 \lambda \eta$; en latín, schola; en castellano, escuela. Así, pues, el nombre con que denominamos los lugares en que se lleva a cabo la educación, e incluso la educación superior, significa ocio. Escuela no quiere decir escuela, sino ocio. (p. 12).

Con esta alianza etimológica, la pregunta evidente es: ¿cuál es el sentido de ocio y cuál el de escuela que enuncian estos autores, si los conceptos actuales divergen al punto de que el ocio es generalmente negado en la escuela?

Por supuesto, no es fácil precisar este sentido, más aún cuando discursos tan dispares recorren la academia. Piénsese, por ejemplo, en el Elogio de la ociosidad que en 1932 hacía Bertrand Russell (1953), a tan solo 33 años del análisis crítico sobre la clase ociosa de Thorstein Veblen (2011). 0 bien, en las apreciaciones de un autor como Manuel Cuenca (2003), basadas en el Estado de bienestar, en el ocio como derecho y como experiencia, y en el énfasis en grupos etarios de las actividades del ocio, en contraposición a los diversos discursos compilados por Osvaldo Baigorria (1995), quien le apunta más bien a la constitución de una sociedad de ocio totalmente opuesta a una sociedad de trabajo (Offe, 1992). Sin embargo, por lo menos tres concepciones sobre la correspondencia entre el ocio y la educación pueden hacerse a partir del estudio sobre los grecorromanos:

(i) El ocio, más que un conjunto de actividades o una experiencia humana, refiere a una actividad vital, o bien, a una forma de vivir, la cual conjuga la interrogación del mundo, la lección educativa, el placer producido por todo ello y el tiempo vital empleado. En este sentido, la ociosidad es el estar siendo en el que los hombres libres se encuentran, dada su condición social y su inclinación 
natural hacia la "contemplación de la verdad, buscar un modelo de vida, y practicarlo en solitario retiro" (Séneca, De Otio, II, 1, 2010, pp. 144-145).

(ii) Pero aún más intrigante y profundo (como se ve, por ejemplo, en el planteamiento aristotélico), el ocio es el principio de todas las cosas, siendo este un análisis más ontológico que teológico, en el sentido de que comprende el mundo pensado y habitado, y no el mundo de las cosas creadas en general. Por ello, siguiendo a Aristóteles, la relación entre educación y ocio es, realmente, esencial: el objetivo de la educación debería ser el obtener una vida de ocio, ya que él contiene el placer y la felicidad, lo que, sobre cualquier otra cosa, es el Bien al que aspira el hombre por naturaleza. Como muestran Maresca, Magliano y Ons (2006), para Aristóteles, en la educación

Deben adquirirse solo los conocimientos que se relacionen con los trabajos útiles pero que no envilezcan, considerándose viles los que incapacitan al cuerpo, al alma o a la mente de los hombres libres para la práctica de las virtudes. Envilecen aquellos trabajos que producen deformaciones en el cuerpo o que se hacen a cambio de un salario. La razón del envilecimiento es que privan a la mente de ocio. Lo propio de los hombres libres es precisamente estar librado de las tareas degradantes que impidan una vida más noble. Una vida de esta naturaleza es la vida en ocio. (p. 120).

Esta no es una mera concepción antigua, por el contrario, se trata de un concepto en sí mismo, esto es, en palabras de Deleuze y Guattari (2005), del corte dentro de un campo de experiencia que sobrepasa, o quiebra la opinión, configurando un trozo del caos. Por ello, esta concepción no es superada por ninguna otra acerca del mismo término, mas es renovada, en cierto modo, por autores como Lafargue (con el término pereza), o Russell, para quien, "sin la clase ociosa, la Humanidad nunca se hubiera elevado sobre la barbarie" (1953, p. 35).

(iii) De este modo, más que sinonimia (o relación etimológica, como suele exponerse), entre el ocio y la escuela existe una relación pragmática, la cual ha de restablecerse en pro de la transformación (constante) de los modos de vivir actuales, esto es, con el fin de realizar mundos posibles. Así las cosas, desde la Educación Física, el Deporte o la Recreación pueden adoptarse estrategias que lleven a proyectos educativos en los que la educación como proceso adquiera la forma (o configuración) del ocio. Ya no se trata solamente de hacer de la escuela un escenario de encuentro, o un lugar de formación en valores como la solidaridad y el trabajo en equipo, sino su modificación estructural. Por ello, la apuesta de Onfray (2008), junto con sus colegas, ha tenido por modelo el jardín de Epicuro, un espacio de revoluciones moleculares con base en la amistad.

Ahora, evidentemente, ocio y pereza, en este sentido, adquieren una condición similar, a pesar de la diferencia en el uso de los términos. Para Lafargue, la pereza no era otra cosa que la "madre de las artes y de las nobles virtudes" (2004, p. 134), contraria totalmente al productivismo exacerbado en el que el obrero (proletariado) luchaba por el trabajo, sin saber que en realidad exigía el derecho a ser esclavo. Y, desde la introducción de su texto, hace referencia a los griegos para demostrar que su idea no es para nada descabellada (si tanto se admira a los griegos clásicos, por qué no se los toma en serio sobre esto). Así las cosas, el ocio, como una suerte de resistencia a la destrucción del cuerpo y al envilecimiento del hombre, según lo dicho arriba, debe tratarse como si fuera la pereza pura. ¡Cómo?! Recordemos las palabras de Estanislao Zuleta:

Lo bueno en el carácter de las regiones [colombianas] que se formaron en la esclavitud, lo meritorio y lo progresista, es la pereza, porque es una manifestación de la dignidad humana, porque es la afirmación de que, cuando uno está interesado en hacer un trabajo, no tiene por qué ser diligente como las mulas, que son muy diligentes en llevar la carga aunque no les interese nada. Los hombres, afortunadamente, no son mulas y por eso son perezosos: porque protestan contra el trabajo que no los transforma y en el cual no está su futuro. Así concebida, la pereza es una protesta interiorizada, un grito de dignidad humana, que choca mucho a los esclavistas pero que es una buena cosa en los esclavos. (2010, p. 37).

Pero entonces, ¿por qué se ha naturalizado la idea de que el ocio y la pereza deben ser totalmente rechazados? Como se ha dicho, es muy probable que fuera en plena decadencia del Imperio Romano, es decir, en medio de la caída del paganismo y del consecuente crecimiento del cristianismo, el momento en que el ocio sufriría una transformación radical, la cual no puede entenderse simplemente como un cambio de significación, ni como un 
señalamiento meramente arbitrario, sino como resultado de un profundo cambio de vida: la transformación hacia el pensamiento cristiano y la intensificación de los ejercicios espirituales de consagración a Dios. Este cambio se puede ver, siguiendo a Foucault $(2005,2009)$, como el paso de una ética de sí mismo a la norma moral, coercitiva y dominante. Por ello, al analizar a uno de los padres de la Iglesia Católica, Agustín de Hipona (quien concebimos precisamente como un importante moldeador de este paso en aquella época), es posible ver los elementos que, atando a la educación con los ejercicios de adoración a Dios, convierten cualquier otra práctica ociosa (denominada otium) en generadora de pecado, esto es, en el distanciamiento del camino correcto para llegar a Dios y cumplir con su ley comportamental.

Agustín permite el desarrollo de una época muy particular en la que la asociación del ocio con los vicios, o con las prácticas perniciosas, modelará un sentido que se propagará en los estudios cristianos sobre el pecado, en claro distanciamiento con la forma de vivir de los grecorromanos. Por supuesto, Agustín no es un punto de origen, sino más bien un nodo, un punto de entrecruzamiento que, de forma muy original, reconfigura cuestiones de sus influencias, entre las que destacan, como se sabe, Platón, Aristóteles, Pablo de Tarso, Cicerón y Virgilio. Empero, su papel es sumamente importante en los periodos posteriores, desde que la Iglesia Católica desarrolla la organización imperial de Roma hasta la terrible figuración literaria de la pereza por parte de Dante Alighieri, según la cual los perezosos sufren bajo un río, en medio del lodo y la porquería, sin siquiera poder respirar, dentro del infierno.

De este modo, en lo que se denomina (no sin cierto sinsabor) la filosofía cristiana, se forjaría una noción de ocio vinculada directamente con la pereza malsana o, como sería más apropiado nombrarla, con la desidia (o acedía, según se ha visto con Bruckner), en tanto esta refiere al abandono (voluntario o pasional) de las tareas del buen cristiano. Si es voluntario, se tratará de flojedad, de debilidad, de cansancio como enfermedad. Si es pasional, tendrá que ver más con la melancolía, con la angustia, con la amargura. En esta lógica, la educación se orientaría (sobre todo en los monasterios) hacia la práctica de ejercicios espirituales, el oficio y la obediencia en la abnegación y, de un modo especial, en la liturgia (destacándose, sin duda, la Eucaristía). Así pues, lo que entre los griegos fue una sola cosa se distanciaría de un modo radical: educación nunca más sería ocio, estando su comprensión más al lado de la schola latina (organización militar o séquito) que del otium.

Muy probablemente por su formación con los maniqueos, en Agustín parece haber un discurso reduccionista del mundo en el que se admitirían dos principios reguladores opuestos, el Bien y el Mal. La idea del Bien, sin duda, se vinculaba con el cumplimiento de la norma, o voluntad divina, mientras que el Mal se asociaba con todo lo contrario. Mas, como no era nada fácil permanecer en el camino, era necesario un esfuerzo continuo denominado trabajo. En sus Confesiones, Agustín (1926) denigra de sus años de infancia y juventud, entregados, entre otras cosas, a los juegos, al estudio de los clásicos, a las fiestas y al amor a las mujeres, cuestiones que lo mantuvieron, según dice, alejado de Dios, generando dolor y sufrimiento a su madre. Con ello, concluye que tal forma de vivir es equivocada, como una suerte de ruina para el hombre. Y promueve, por tanto, el arrepentimiento y la obediencia.

Ahora bien, a pesar de ello, por ejercicio no se referenciaba únicamente la continuidad y el esfuerzo en las tareas y actividades religiosas. Esto era, más bien, una suerte de consecuencia. De hecho, la vinculación del ejercicio con el movimiento del cuerpo responde a una época posterior, en la que, además de descubrirse las conexiones del sistema nervioso con el muscular, se considera como un método más apropiado para la corrección del hombre (Vigarello, 2005a y 2005b). La noción de ejercicio estaba entonces más relacionada con la quietud, es decir, se trataba de un ejercicio pasivo (o meditatio) en el cual era importante mantenerse, por ejemplo, arrodillado ante el altar. De allí que se tratara de una vida performativa, como ha mostrado Sloterdijk (2012).

Sin embargo, de acuerdo con todo esto, ejercitarse en el Bien no dependía de los resultados, de los efectos sobre uno mismo o sobre los demás, ya que el Bien era definitivo, estaba preconcebido, era indubitable. No habría que preguntar qué de lo que hago me hace bien, como en cierto modo parece era la pregunta base de los grecorromanos, a la cual respondían de diversos modos como, por ejemplo, la vida pública o la participación política (praktikós bíos o vita activa), según los estoicos, o bien, la vida contemplativa o teórica (theorçtikós bíos), de acuerdo con Aristóteles y los suyos, o la vida 
placentera (apalaustikós bíos), a la que se inclinaban más los epicúreos. En la decadencia del Imperio, el Bien se iba forjando como una sola y única cosa para todos, la cual, en Agustín, no era más que estudiar la Biblia y seguir los preceptos cristianos (dicho de un modo explícito que, no obstante, es necesario ver detenidamente).

Se entiende, así, lo difícil que resulta empezar a emplear un término de un modo distinto al acostumbrado y, más aún, vivir de acuerdo con este nuevo sentido que se le da. Es más fácil mantener vivo el sentido de las cosas tal como las creemos (como nos las enseñaron) que hacer el esfuerzo de contrarrestarlas e inventar nuevas formas de vivir de acuerdo con su misma novedad, porque no dependen de ellas mismas, ni tan solo de la exoconsistencia formada a partir de su relación con otros conceptos, sino de uno que resulta radical para el comportamiento humano: la idea del Bien. No solo ante el temor que suscita el sufrimiento eterno después de la muerte, sino el de no ser digno de salvación alguna, la estrategia cristiana impide que uno haga lo que, en realidad, lo nutre, lo enriquece, lo empodera. Y, de allí, el señalamiento al ocio, la negación de la pereza y la traba a la transformación de la escolaridad. Hay que transitar, entonces, los pormenores de la cuestión y analizar con delicada prudencia los periodos que nos remiten a una ociosidad o a otra para poder ofrecer alternativas bien fundadas.

\section{DERROTEROS INVESTIGATIVOS}

Las apreciaciones aquí consignadas, en la medida que han surgido de un proyecto de investigación en curso, son apenas entremeses de una apuesta educativa por realizar, así como de la continuidad de indagaciones de los fundamentos que, conforme a la confianza que nos proporcionan, son poco cuestionados. Consideramos que la importancia de este análisis para la Recreación (así como para la Educación Física y el Deporte) es que la expresión ocio suele usarse con regularidad en un sentido más bien abstracto. Se juega contra el uso peyorativo, pero se defiende sin pleno conocimiento sobre su historia y los problemas a los que da lugar (de los que proviene y que ha atravesado). Además de que discusiones importantes sobre este quedan las más de las veces circunscritas a un pequeño grupo de especialistas. Una visión más detallada del asunto, entonces, permitirá la generación de propuestas educativas (y escolares) de mayor envergadura, atinentes a la consecución de un mundo distinto, en clara resistencia a (lo peor de) la sociedad actual, pero sin el establecimiento de una sociedad ideal, sino más bien, como ya puede decirse, de una sociedad ociosa (inventiva, diferenciante, convivencial). En palabras de Iván Illich (2006), una Edad de Ocio.

Resulta imprescindible tratar especificidades, con base en una perspectiva general, que permitan conocer no solo la perspectiva griega (que igual no es homogénea) sobre el ocio, sino aquella que se presenta en filósofos particulares como Aristóteles, Epicuro y en los cínicos, como ejemplo. Asimismo, sin dejar de ver la historia en perspectiva de largo alcance, es necesario buscar esos puntos de quiebre, esos nodos en los que una concepción se forja, o bien, se imprime dentro de las opiniones, las costumbres y las pasiones de los individuos. Esto permitirá, de seguro, emprender análisis de corte multicultural, en el sentido de extrapolar nociones propias de Occidente a contextos, a formas de vivir, que, pese a ciertas similitudes, tienen muy poco de ello. No cabe duda que tales estudios son necesarios para conseguir el mismo propósito que aquí se ha señalado varias veces, posibilitar nuevas formas de ser conforme una crítica constante a las formas que se acostumbran. Y, finalmente, con toda seguridad, esta urdimbre de indagaciones e interrogantes ha de procurar un escenario adecuado para atender, y/o proponer, un ocio poshumano al que se va llegando con más rapidez que la pensada, a partir del reemplazo del hombre por parte de las máquinas en el trabajo, y a la inexorable contradicción entre el adormecimiento vía medios de comunicación y la exigencia de ganancia económica, cada vez con mayor urgencia.

\section{REFERENCIAS}

Abenshushan, V. (2013). Escritos para desocupados. México: Surplus Ediciones.

Acosta, L. (2002). La recreación: una estrategia para el aprendizaje. Colombia: Editorial Kinesis.

Agustín de Hipona (San). (1926). Confesiones. Trad. R. P. Fr. Eugenio Zeballos. Barcelona: Librería Religiosa.

Applebaum, H. (1992). The Concept of Work. Ancient, Medieval and Modern. Nueva York: State University of New York.

Ariés, P. (1987). El niño y la vida familiar en el Antiguo Régimen. Madrid: Taurus.

Baigorria, O. (1995). Con el sudor de tu frente. Argumentos para la sociedad del ocio. Argenta: La Marca. 
Bolaños, T. (2005). Quehacer del ocio: elementos teóricos de recreación. Armenia: Editorial Kinesis.

Bonilla, C. (s. f.). Pedagogía y cultura física. Una mirada crítica a la educación física y el deporte. Colombia: Revista Kinesis.

Bruckner, P. (2001). La euforia perpetua. Sobre el deber de ser feliz. Barcelona: Tusquets Editores.

Chartier, R. (2006). Escribir las prácticas: Foucault, De Certeau, Marin. Argentina: Ediciones Manantial.

Cuenca, M. (2003). Ocio humanista. Dimensiones y manifestaciones actuales del ocio. Bilbao: Universidad de Deusto.

De Landa, M. (2011). Mil años de historia no lineal. México: Gedisa.

Deleuze, G. y Guattari, F. (1995). El Anti-Edipo. Capitalismo y esquizofrenia. España: Ediciones Paidós Ibérica.

Deleuze, G. y Guattari, F. (1997) Mil Mesetas. Capitalismo y esquizofrenia 2. Madrid: Pre-Textos.

Deleuze, G. y Guattari, F. (2005). ¿Qué es la filosofía? Barcelona: Editorial Anagrama.

De Waal, F. (2002). El simio y el aprendiz de sushi. Reflexiones de un primatólogo sobre la cultura. Barcelona: Editorial Paidós.

Elizalde, R. y Gomes, C. (2010). Ocio y recreación en América Latina: conceptos, abordajes y posibilidades de resignificación. Polis (Santiago), 9(26), pp. 19-40. Recuperado de: http://www. scielo.cl/scielo.php?script=sci_arttext\&pid=S071865682010000200002\&lng=es\&tlng=es. 10.4067/ S0718-65682010000200002.

Forero-Nougués, M. (2004). Historia de tres mundos: cuerpo, cultura y movimiento. Reflexiones de cultura física. Bogotá: Universidad Santo Tomás.

Foucault, M. (2005). El uso de los placeres. Historia de la sexualidad 2. México: Siglo XXI Editores.

Foucault, M. (2008). Nietzsche, la genealogía, la historia. Madrid: Pre-Textos.

Foucault, M.(2009). Elyo minimalistayotras conversaciones. Argentina: La Marca.

Gerlero, J. (2005). Diferencias entre ocio, tiempo libre y recreación: Lineamientos preliminares para el estudio de la Recreación. I Congreso departamental de recreación de la Orinoquia colombiana. Villavicencio, Meta. Octubre 20 - 22 de 2005. Recuperado de: http://www.redcreacion.org/documentos/cmeta1/JGerlero.html

Illich, I. (2006) La sociedad desescolarizada. Obras Reunida Vol. 1. México: Fondo de Cultura Económica.
Lafargue, P. (2004). El derecho a la pereza. Argentina: Longseller.

Maresca, S., Magliano, R. y Ons, S. (2006). Placer y bien. Platón, Aristóteles, Freud. Argentina: Editorial Biblos.

Meinel, K. (1998). Didáctica del movimiento. Ensayo de una teoría del movimiento en el deporte desde el punto de vista pedagógico. Colombia: Zambon Verlag.

Offe, C. (1992). La sociedad del trabajo. Problemas estructurales y perspectivas de futuro. España: Alianza Editorial.

Onfray, M. (2008). La comunidad filosófica. Manifiesto por una Universidad Popular. Barcelona: Editorial Gedisa.

Pedraz, M. (2006). Arqueología de la educación física y otros ensayos. Armenia: Editorial Kinesis.

Pérez de Ayala, R. (1975). Viaje entretenido al país del ocio. Madrid: Ediciones Guadarrama.

Pieper, J. (2003). El ocio y la vida intelectual. Madrid: Ediciones Rialp.

Rodríguez, J. (1998). Deporte y ciencia. Teoría de la actividad física. Barcelona: Inde.

Russell, B. (1953). Elogio de la ociosidad y otros ensayos. Madrid: Aguilar Ediciones.

Séneca. (2010). Sobre el ocio. España: Alianza Editorial.

Sloterdijk, P. (2012). Has de cambiar tu vida. España: PreTextos.

Sue, R. (1987). El ocio. México: Fondo de Cultura Económica.

Veblen, T. (2011). Teoría de la clase ociosa. Madrid: Alianza Editorial.

Vega R. (2007). Un mundo incierto, un mundo para aprender y enseñar. Las transformaciones mundiales $y$ su incidencia en la enseñanza de las Ciencias Sociales. Vol. 2. Universidad Pedagógica Nacional. Bogotá: Editorial Nomos.

Vigarello, G. (2005a). Corregir el cuerpo. Historia de un poder pedagógico. Buenos Aires: Ediciones Nueva Visión.

Vigarello G. (2005b). Ejercitarse, jugar. Historia del Cuerpo, Vol. I. España: Taurus.

Vigarello y Holt. (2005). El cuerpo cultivado: gimnastas y deportistas en el siglo XIX. Historia del Cuerpo, Vol. II. España: Taurus.

Zuleta, E. (2010). Tres culturas, tres familias y otros ensayos. Medellín: Fundación Hombre Nuevo Editores. 